\title{
ENGLISH COMPOUND WORDS USED IN THE JAKARTA POST HEALTH COLUMN ON THIRD WEEK OF APRIL 2020
}

\author{
Felix Stefani Sisvinda ${ }^{1}$ \\ ${ }^{1}$ Universitas Sanata Dharma \\ ${ }^{1}$ flxstefani@gmail.com
}

\begin{abstract}
This study aims to describe the formation and the meaning of compound words that related to COVID19 pandemics used in The Jakarta Post's Health Column Article on Third Week of April 2020. There are two research question in this study: (1) What are the type of COVID-19 compound words and their lexical categories found in The Jakarta Post's Health Column Article on Third Week of April 2020, and (2) How does those related COVID-19 compound words create meaning. To answer the research question, the writer uses the theory of morphology and semantics. The findings showed that there are 26 compound words in The Jakarta Post's Health Column on the third week of April 2020. Based on the type of compound words, there are $86.4 \%$ compound noun, $11.5 \%$ compound adjective, and $3.9 \%$ compound verb. The most dominant lexical category is from compound nouns which are Noun+Noun and Adjective + Noun. Based on the meaning of compound words, there are are $80.76 \%$ endocentric compounds and $19.24 \%$ exocentric compounds.
\end{abstract}

Keywords: Compound words, COVID-19, Morphology, Semantics

\section{INTRODUCTION}

Language is defined merely as a system of communication, or the ability to produce speech sounds. (Fromkin, 2014:26) It shows that language often viewed as a vehicle of thought, a system of expression that mediates the transfer of thought from one person to another. (Finegan, 2008:6) As its function for communication, language holds an important role. It allows human to share ideas and express their feelings. As human is also a social creature, language makes human able to interact and build a greater emotional bound to others.

Nowadays, the information transferring process can be done easily through technology. People can get information or even interact with others through electronic devices or even from printed media. The pace of sharing information is fast and available for all people. It enables them to get a factual information from other countries in seconds. However, since many hoaxes spread, people should get the information from reliable sources such as newspaper.

The development of newspapers nowadays gradually develop from printed to online form. People also may obtain up to date and reliable information about local or international events every day. These conditions show the globalization era really help us to reach as many as possible information from other. As consequences, some newspapers are producing news in English language. There is a well-known news media in Indonesia that use English language called The Jakarta Post.

The Jakarta Post is a daily English newspaper in Indonesia which comes in two forms: printed and online. The whole news in The Jakarta Post is written in English language by both Indonesian and native speaker journalists. It has many kinds of column on the website such as 
worldwide, health, politics, economic, and etc. Having many variations topics in the column, The Jakarta Post is expected to use a proper and well written English. Especially when it comes to discuss the most recent COVID-19 pandemic outbreak. COVID-19 is an infectious pandemic disease that started in Wuhan China. It spreads rapidly and becomes a dangerous outbreak around the world. It gets so much worse when the disease not only affect the victims, but also the education, social, and economic system. Since, the number of victims is increasing every day and many government policies are adjusting, newspaper is expected to give informative and credible news to people. Because it will successfully deliver important information about the outbreak to the public. From here, we know that the use of language is important, as well as the linguistic aspect that support it.

The linguistic aspect in English language covers grammatical rules which essential to construct the sentence. Nevertheless, even if they are grammatically right, the word form and the sentence structure may contribute to ambiguity. This is attributed to ambiguity in lexicon or grammar. Because of the vague terms, phrases and sentences people can have different meanings. Compound words in this case can be one of the ambiguity causes. It is because compound words in English have its own formation rules and sometimes it looks similar with noun phrases. Due to this reason, the writer decided to conduct a research on the formation and the meaning of compound words found in The Jakarta Post's health column on the third week of April 2020. The data in this study is limited on the newest issue articles of COVID-19 and related compound words of coronavirus.

Previously, there are several studies that also discussed about compound words. First, the research was conducted by Christianto (2019), he conducted a theoretical study on compound words. He investigated the types of English compounds and the lexical categories which are resulted from the process of compounding. The data he used are taken from several resources such as books, journal articles, and online websites. The data is not taken from specific source because this is a theoretical study which aims to develope linguistic knowledge in general and concrete models (Bussman, 1998). The result reveals that (1) there are endoncentric and exocentric compound word types, and (2) the lexical items occurred in compounding process are noun compound, verb compound, and adjective compound.

The second study was conducted by Rahayu (2016) about morphological analysis on English compound words in five articles of BBC. The choice of object in this study is more specific than previous one. In this study, Rahayu limits the research only on five news foun in BBC websites. She examined the types, the orthographic features, and the meanings of compounds. The result of the study shows that there are five types of compounds in the selected articles (compound nouns, compound verbs, compound adjectives, neo-classical compounds, and other form classes) and compound noun is the most dominant types. It also reveals that compounds which are complex tend to be written separately instead of written as one word or hyphenated. Compounds which are written as a one word, tend to be classified as exocentric compounds and compounds which are written separately, tend to be classified as endocentric compounds. The analysis in this study is more detail, because Rahayu (2016) counted the syllables of every selected compound words which makes the study is more reliable.

The last related study the writer has found is from Nurhazizah (2018) which examined the forms of compound words and the meaning of compound words found in Republika news article. Different with two previous studies, this study also examined the meaning of the compound words. Nurhazizah (2018) used 11 data compound words in Republika news article. The study reveals that there are three forms of compound words, which are Noun compound ( 7 data), Verb 
compound (3 data), and Adjective compound (1 data). Then, the meaning of compound words is mostly categorized as 7 transparent meaning than opaque meaning.

\section{LITERATURE REVIEW}

This study examines the formation and the meaning of compound words by using two branches of linguistics study. Two main linguistic study which is suitable for this study are morphology and semantics. Morphology is the study of the internal structure of words. (Bauer, 2004:282) It means that the formation of words can be analysed by using morphology. To understand morphology, it is better to understand morphemes.

Morpheme is a minimal linguistic unit or the minimal units of meaning. (Fromkin, 2014:37) There are two kinds of morpheme, free morpheme, and bound morpheme. Free morphemes are those that can occur as an independent word such as chair, table, flower, for. Otherwise, bound morphemes cannot occur as an independent word but must be attached to another morpheme, such as affixes (prefixes and suffixes), infixes, and circumfixes. (Finegan, 2008:62)

In order to create a new meaningful word, those morphemes are combined each other. The process of combining morphemes generally called word formation. There are many varieties of word formation, such as borrowings, clippings, blends, compounding, narrowing, and broadening. However, the researcher only focused on compounding process.

Compounding process is a process when new words can be formed from already existing words, in which individual words are coined together to form a compound word. (Akmajian, 2010:35) Moreover, compound word is a meaningful new word that is formed by two or more different existing words which undergone a process of compounding. (Akmajian, 2010:35) For example, the noun hand can be joined with the verb wash to form a compound verb handwash. Moreover, according to Matthews (1974: 82) compounding is a mechanism by which a compound lexeme is produced from two or more simpler lexeme. It means that the process of compounding here can be derived both from lexeme or word. Compound word is also known as a common technique for word building in English. The result of word compounding can be various such as noun, adjectives, verb, and noun. It can also produce preposition like into or onto. In representing compound words, English otnography is not consistent. The form of compound words can be written as a single word, with a hyphen, and as separate words. Another distinguishing characteristic of compounds in English is it usually difficult to apply tense and plural symbols to the first element while they may be attached to the compound as a whole.

There are three types of compound words, compound noun, compound adjective, and compound verb. Compound noun is made up of two more words functions as a noun. (McCharty, 2001:28) These words may be joined together as in teabag, or hyphenated, as in baby-sitter, or sometimes two or more that are separate and refer to one thing such as baked beans, or bacon and eggs. (Winch, 11) Moreover, a compound adjective is made of two parts and it is usually written with a hyphen, e.g., shocking-pink, never-ending, and well-dressed. The meaning of compound adjective mostly clear from the words that combined. (McCharty, 2001:26) Lastly, a compound verb is a fixed expression which is made up more than one word and functions as a verb such as in sky-dive and overeducate. (McCharty, 2001:40)

As morphology is the study of the systematic relationship between the form and meaning of complex words (Booij, 2005:47), it is also better to conduct a research on the meaning. Compound words such as blackboard, boathouse, and bedroom all have relatively 
straightforward relationships between their constituent and whole-word representations. However, even for the relatively uncomplicated compounds above, some reflection leads us to the conclusion that the meaning of the compound word cannot simply be derived from the meanings of its parts such as droplet, redhead, and paperback. (Libben, 2006: 28) Hence, the meaning of compound words need to be investigated further.

Semantics is the systematic study of meaning, and linguistic semantics is the study of how languages organize and express meanings. (Krediler, 2002:3) Through this study, meaning analysis of compound words is very possible to conduct. Linguists has identified three forms of compound words depending on the various semantic relations between the head and modifier(s), these are endocentric compounds and exocentric compounds.

According to Katamba (1993: 305) endocentric compound is the most compound type in English. They have a head in its structure. In this compound, the head element appears as the right-hand most constituent of the word. The head here will determine the category of a whole compound word. For example, is the compound word over react. This compound word consists of preposition over and verb react. Since over react is verb, hence, it can be concluded that react is the head of this endocentric compound word.

Furthermore, exocentric compounds or bahuvrihi compounds are headless compounds. It does not contain an element that function as the semantic head which is modified by the nonhead element. For example, the word greenhouse does not specify a house with green colour. Nevertheless, the word greenhouse refers to the building where plants are grown. It happened because the constituents in these exocentric compounds do not have a head-modifier semantic relationship. Semantically, exocentric compounds are opaque. Their meaning mostly cannot be apparently guessed from its constituent parts like idioms.

\section{METHOD}

The writer decided to choose articles in The Jakarta Post as the material for the research because this media is a well-known English newspaper in Indonesia. The data used in this study were taken from The Jakarta Post official website, especially from Health column articles on the third week of April. Health column in The Jakarta Post is discussing various topics, however, there were only articles that talk about COVID-19 started from April $12^{\text {th }} 2020$ until April $18^{\text {th }} 2020$ that used in this study. The writer does not limit the amount of the articles that used, since the number of compound words in one article are limited. In this study, the writer used 18 articles. However, the limitation will be on the choice of compound words. The writer only includes compound words that related to COVID-19 and omitted unrelated compound words. The words chosen were also based on the writer's personal experiences during the pandemic.

There are several steps that had done by the writer in this study: (1) the writer were collecting the articles from the website, (2) the writer read the whole articles and identify the compound words, (3) the compound words found in COVID-19 articles were collected and categorized into each word class, (4) the writer analyse each compound words' lexical categories, and (5) the analysis of compound words are continued by the discussion of the meaning.

In this study, the researcher uses morphology and semantic study as the literature review. Most of the literature reviews are taken from online journals and e-book. Researcher also use four main online dictionaries for analysing the compound words. There are Cambridge online 
dictionary, Oxford learners' dictionary, Merriam-Webster online dictionary, and Longman Dictionary of Contemporary English. The writer chose 26 words to be analysed as in Table 1 .

Table 1. Common COVID-19-Related Words

\begin{tabular}{clll}
\hline 1. & Blood-brain-barrier & 14. & Mental health \\
\hline 2. & Coronavirus & 15. & Micro-needle \\
\hline 3. & Droplet & 16. & Microbiology \\
\hline 4. & Drug maker & 17. & Outbreak \\
\hline 5. & Face mask & 18. & physical distancing \\
\hline 6. & Face-to-face & 19. & Self-isolation \\
\hline 7. & Fallout & 20. & sunbathing \\
\hline 8. & Hand sanitizer & 21. & Shortage \\
\hline 9. & Handwash & 22. & Social distancing \\
\hline 10. & Healthcare & 23. & Sunbathe \\
\hline 11. & Health insurance & 24. & Sunlight \\
\hline 12. & Life science & 25. & Well-being \\
\hline 13. & Long-term & 26. & Worldwide \\
\hline
\end{tabular}

\section{RESULTS AND DISCUSSION}

The findings and discussions are divided into the formations of compound words and the analysis of compound words meaning. The first discussion is based on morphology study, and the second analysis of meaning will be based on semantic study.

\section{Results}

\section{The Lexical Categories of Compound Words}

There are 26 compound words which related to COVID-19 found in 18 articles of The Jakarta Post's health column. There are four kinds of compound words occurred in the articles which are compound nouns, compound adjectives, compound verbs, and compound adverb. The distribution of compound words is displayed in table 2 .

Table 2. The Distributions of Compound Words

\begin{tabular}{cccc}
\hline No. & Word Class & Frequency & \% \\
\hline 1. & Noun & 22 & 84.60 \\
2. & Adjective & 3 & 11.50 \\
3. & Verb & 1 & 3.90 \\
\hline & Total & 26 & 100.00 \\
\hline
\end{tabular}

From the result, it shows that the compound noun is the most dominant compound. There are 26 compound nouns which are distributed in The Jakarta Post's Health Column and they have percentage about $84.60 \%$. Then, it is followed by compound adjectives. There are 3 compound adjectives and have percentage about $11.50 \%$. The last is compound verb which are the least compounds in the articles. There is 1 compound verb and it has percentage about $3.90 \%$.

Compound Nouns 
A compound noun is an expression which is made up of more than one word and functions as a noun. (McCharty, 2001:28) For example, the noun word haircut are made up from a noun hair and a verb cut. The formation of compound nouns can be various. There are 7 different lexical categories found in compound noun formation that can be seen in table 3 .

Table 3. The Distribution of Compound Noun Formation

\begin{tabular}{cccc}
\hline No. & Lexical Categories & Frequency & \% \\
\hline 1. & $\mathrm{~N}+\mathrm{N}$ & 14 & 63.63 \\
2. & $\mathrm{~A}+\mathrm{N}$ & 3 & 13.67 \\
3. & $\mathrm{~V}+\mathrm{V}$ & 1 & 4.54 \\
4. & $\mathrm{~V}+\mathrm{ADV}$ & 1 & 4.54 \\
5. & $\mathrm{ADV}+\mathrm{V}$ & 1 & 4.54 \\
6. & $\mathrm{~N}+\mathrm{N}+\mathrm{N}$ & 1 & 4.54 \\
7. & $\mathrm{ADV}+\mathrm{N}$ & 1 & 4.54 \\
\hline \multicolumn{2}{r}{} & 22 & 100.00 \\
\hline
\end{tabular}

Compound Adjective

A Compound adjective is made of two parts and it is usually written with a hyphen, e.g. shocking-pink, never-ending, and well-dressed. The meaning of compound adjective mostly clear from the words that combined. (McCharty, 2001:26) There are four lexical categories of compound adjectives found in The Jakarta Post's Health Column articles, which are $\mathrm{N}+\mathrm{P}+\mathrm{N}$, $\mathrm{N}+\mathrm{V}, \operatorname{Adj}+\mathrm{N}$, and $\mathrm{N}+\mathrm{Adj}$.

Table 4. The Distribution of Compound Adjective Formation

\begin{tabular}{cccc}
\hline No. & Lexical Categories & Frequency & \% \\
\hline 1. & $\mathrm{~N}+\mathrm{P}+\mathrm{N}$ & 1 & 33.33 \\
2. & $\mathrm{Adj}+\mathrm{N}$ & 1 & 33.33 \\
3. & $\mathrm{~N}+\mathrm{Adj}$ & 1 & 33.33 \\
\hline & Total & 3 & 100.00 \\
\hline
\end{tabular}

\section{Compound Verb}

A compound verb is a fixed expression which is made up more than one word and functions as a verb. (McCharty, 2001:40) A compound verb can be formed by several lexical categories. However, in this study, there is only one lexical category which is $\mathrm{N}+\mathrm{V}$.

Table 5. The Distribution of Compound Verb Formation

\begin{tabular}{cccc}
\hline No. & Lexical Categories & Frequency & \% \\
\hline 1. & $\mathrm{~N}+\mathrm{V}$ & 1 & 100.00 \\
\hline & Total & 1 & 100.00 \\
\hline
\end{tabular}

\section{The Meaning of Compound Words}

In this part, the researcher discusses the meaning of compound words. The analysis of meaning is classified into two categories which are endocentric and exocentric compound. The distribution of compound words meaning is displayed in the table 6. 
Table 6. The Distributions of Compound Words Meaning

\begin{tabular}{|c|c|c|c|c|c|}
\hline No. & $\begin{array}{c}\text { Type of } \\
\text { Compound } \\
\text { Words' } \\
\text { Meaning }\end{array}$ & $\begin{array}{l}\text { Type of } \\
\text { Compound } \\
\text { Words }\end{array}$ & Frequency & Total & $\%$ \\
\hline \multirow{3}{*}{1.} & \multirow{3}{*}{ Endocentric } & Noun & 17 & \multirow{3}{*}{21} & 80.76 \\
\hline & & Adjective & 4 & & \\
\hline & & Verb & 1 & & \multirow{3}{*}{19.24} \\
\hline \multirow{3}{*}{2.} & \multirow{2}{*}{ Exocentric } & Noun & 5 & \multirow{2}{*}{5} & \\
\hline & & Adjective & 1 & & \\
\hline & \multicolumn{2}{|c|}{ Total } & 26 & 26 & 100.00 \\
\hline
\end{tabular}

Based on the result, endocentric compound is more dominant than exocentric compound. There are 21 endocentric compounds found in 18 articles of The Jakarta Post Health Column. It has percentage about $80.76 \%$. Meanwhile, there are only 5 exocentric compound and has percentage about $19.24 \%$. The analysis of both compound words meaning category will be explained further in the following paragraphs.

\section{Discussion}

\section{The Lexical Categories of Compound Words}

\section{Compound Noun}

Based on the result, there are 2 formations that dominate the lexical categories. There are 14 noun + noun, and 3 adjective + noun. The rest of formation only occurred once in the articles.

Noun + Noun

"Sleep won't cure the coronavirus but it can help our bodies fight it." (Excerpt 1)

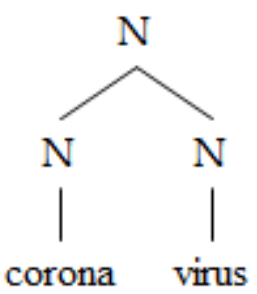

The morphological process of coronavirus is corona $(\mathrm{N})$, and then it is combined with virus $(\mathrm{N})$. The first lexeme is corona $(\mathrm{N})$ and it is a free morpheme because it can stand alone. Then the second lexeme is rock $(\mathrm{N})$ and it is also a free morpheme.

Adjective + Noun

"The advantage of our micro-needle delivery system is that it is relatively straight forward to make and uses very little antigen." (Excerpt 2)

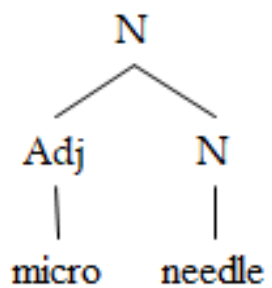


The morphological process of hyphenate compound micro-needle is micro (Adj), and then it is combined with needle (N). The first lexeme is micro (Adj) and it is a free morpheme because it can stand alone. Then the second lexeme is needle $(\mathrm{N})$ and it is also a free morpheme.

Verb + Verb

"The study found that virus transmission in this outbreak could not be explained by droplet transmission alone." (Excerpt 3)

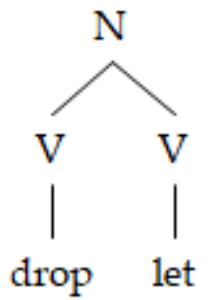

The morphological process of droplet is drop (V), and then it is combined with let (V). The first lexeme is drop and it is a free morpheme because it can stand alone. Then the second lexeme is let and it is also a free morpheme.

Verb + Adverb

"COVID-19 to have 'profound' mental health fallout." (Excerpt 4)

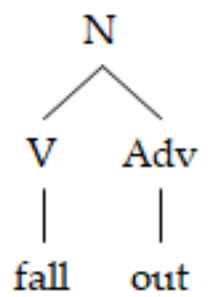

The morphological process of fallout is fall (V), and then it is combined with out (Adv). The first lexeme is fall and it is a free morpheme because it can stand alone. Then the second lexeme is out and it is also a free morpheme.

Adverb + Verb

"The study found that virus transmission in this outbreak could not be explained by droplet transmission alone." (Excerpt 5)

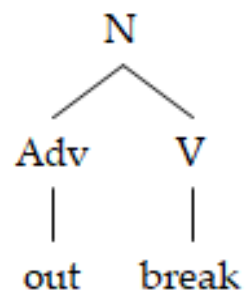

The morphological process of outbreak is out (Adv), and then it is combined with break (V). The first lexeme is out and it is a free morpheme because it can stand alone. Then the second lexeme is break and it is also a free morpheme.

Noun + Noun + Noun

"The brain is protected by something called the blood-brain barrier, which blocks foreign substances but could be breached if compromised." (Excerpt 6 ) 


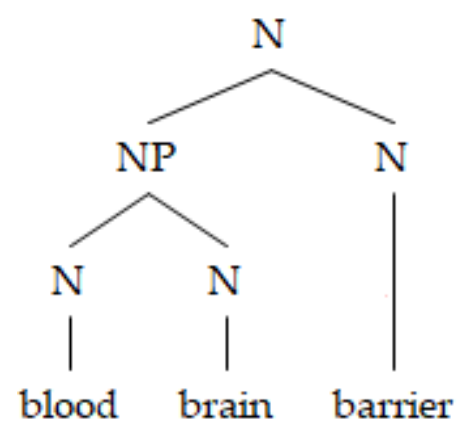

The morphological process of blood-brain barrier is blood-brain (Noun Phrase), then it is combined with barrier $(\mathrm{N})$. The word blood-brain contains two lexemes which are blood $(\mathrm{N})$ and barrier $(\mathrm{N})$. The word blood is a free morpheme because it can stand alone. Then, the second word brain is a free morpheme, because it also can stand alone. The last lexeme is barrier. The word barrier is also categorized as free morpheme.

Adverb + Noun

"In a paper published in Lancet Psychiatry, a panel of 24 specialists call for more funding for research into the impacts COVID-19 may have on society's mental well-being." (Excerpt 7)

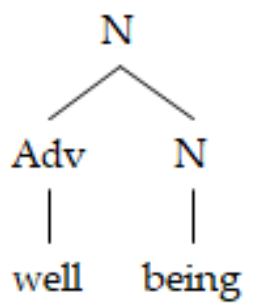

The morphological process of hyphenate compound well-being is well (Adv), and then it is combined with being $(\mathrm{N})$. The first lexeme is well and it is a free morpheme because it can stand alone. Then the second lexeme is being and it is also a free morpheme

\section{Compound Adjective}

Based on the results of the compound adjective in table 4, there are four lexical categories of compound adjectives found in The Jakarta Post's Health Column articles, which are $\mathrm{N}+\mathrm{P}+\mathrm{N}$, $\mathrm{N}+\mathrm{V}, \operatorname{Adj}+\mathrm{N}$, and $\mathrm{N}+\mathrm{Adj}$.

Noun + Preposition + Noun

"The vending machines are part of a bid by the authorities in Taiwan to reduce face-toface contact and make surgical masks more accessible to the public while sticking to the rationing policy on the island." (Excerpt 8)

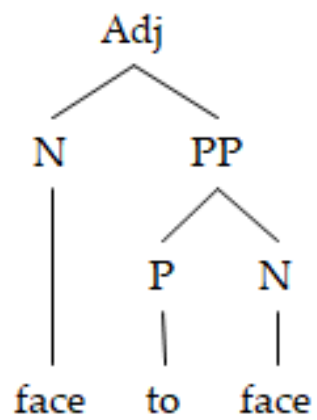


The morphological process of hyphenate compound face-to-face is face $(\mathrm{N})$, and then it is combined with prepositional phrase which consists of to (Preposition) and face $(\mathrm{N})$. The first lexeme is face and it is a free morpheme because it can stand alone. Then the second lexeme is to and the third lexeme is face are also free morpheme.

Adjective + Noun

"A study warns of long-term neuropsychiatric risks among people recovering from COVID-19” (Excerpt 9)

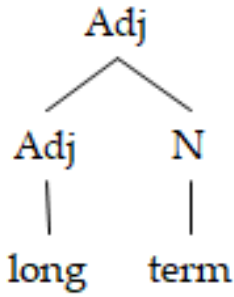

The morphological process of hyphenate compound long-term is long (Adj), and then it is combined with term $(\mathrm{N})$. The first lexeme is long and it is a free morpheme because it can stand alone. Then the second lexeme is term and it is also a free morpheme.

Noun + Adjective

"We believe that our results are relevant to the control of the novel coronavirus that is spreading at pace worldwide." (Excerpt 10)

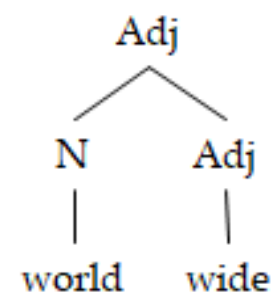

The morphological process of worldwide is $\operatorname{world}(\mathrm{N})$, and then it is combined with wide (Adj). The first lexeme is world and it is a free morpheme because it can stand alone. Then the second lexeme is wide and it is also a free morpheme.

\section{Compound Verb}

Based on the result on the table 5, there is only one lexical category of compound verb which is $\mathrm{N}+\mathrm{V}$.

"Make time to sunbathe."

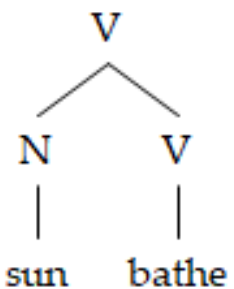

The morphological process of sunbathe is sun $(\mathrm{N})$, and then it is combined with bathe $(\mathrm{V})$. The first lexeme is sun and it is a free morpheme because it can stand alone. Then the second lexeme is bathe and it is also a free morpheme 


\section{The Meaning of Compound Words}

Based on the result, endocentric compound is more dominant than exocentric compound. There are 21 endocentric compounds found in 18 articles of The Jakarta Post Health Column. It has percentage about $80.76 \%$. Meanwhile, there are only 5 exocentric compound and has percentage about $19.24 \%$. The analysis of both compound words meaning category will be explained further in the following paragraphs.

\section{Endocentric Compound}

Endocentric compound is a compound which the meaning can be derived from its head. The examples and formations of endocentric compounds are presented as follows:

\section{Coronavirus}

The compound word coronavirus $(\mathrm{N})$ consists of two lexemes, corona $(\mathrm{N})$ and virus $(\mathrm{N})$. Based on Oxford Dictionary, the meaning of corona is a ring of light seen around the sun or moon, especially during an eclipse. It is also defined as an infection with or disease caused by a coronavirus. Then, the meaning of virus is a living thing, too small to be seen without a microscope that causes disease in people, animals and plants. Meanwhile, coronavirus has a meaning of a type of virus that can cause pneumonia and other diseases in humans and animals. Hence, it can be concluded that the meaning of corona is related to its head which is virus. In other words, it means the virus that is called corona. The meaning of corona here is more relevant to a disease or virus rather than a ring of light during an eclipse. This is why coronavirus is categorized as endocentric compound.

Face mask

The word face mask consists of two lexemes which are face $(\mathrm{N})$ and mask $(\mathrm{N})$. Face means the front part of the head, where the eyes, nose and mouth are. Then, mask means something that you wear over your face to hide it, or to frighten or entertain other people. Meanwhile, face mask is a device worn over the nose and mouth to prevent you from breathing in harmful substances, such as bacteria or pollution, or from breathing bacteria or viruses onto anyone else. It also defined as a covering worn over all or part of the face to hide it. From the meaning interpretation of the head (mask) and modifier (face), it can be concluded that this word is endocentric compound. Because the meaning can be taken literally from the head (mask), and explained deeper by the existence of its modifier (face). It also means the word face mask is right headed-compound.

\section{Handwash}

The compound word handwash is having two lexemes which are hand $(\mathrm{N})$ and wash $(\mathrm{V})$. The word hand means the part of the body at the end of the arm, including the fingers and thumb. The second word wash means to make something/somebody clean using water and usually soap. Furthermore, after the compounding process, the word handwash means an act of washing your hands. The meaning of wash that dominates the general meaning of the whole word handwash shows that it is an endocentric compound word. In other words, handwash means an action of washing hand. It is right-head compound which is categorized as an endocentric compound.

\section{Self-isolation}

The compound word of self-isolation consists of two lexemes. The first is self $(\mathrm{N})$ and the second is isolation $(\mathrm{N})$. The word self is used to refer to a person. The word isolation means the 
act of separating somebody/something. Then, self-isolation is the act of avoiding contact with other people in order to prevent the spread of infection. From here, it is apparent that the meaning of the word can be understood from its right head isolation and becomes the reason why it is categorized as endocentric. The word self also functions as modifier and explain more the meaning of the head. Therefore, we can understand what kind of isolation it is.

\section{Long-term}

The compound word of long-term consists of two lexemes which are long (Adj) and term $(\mathrm{N})$. The definition of long when it is related to time, it means lasting or taking a great amount of time or more time than usual. The word term here means a period of time for which something lasts or a fixed or limited. The word long-term means over a long period of time. Through the definition of each word, there is a close relation between long and term. It is not difficult to take a definition when both words are combined because it can be understood by understand its right head term. Hence, long-term is considered as endocentric compound.

\section{Exocentric Compound}

Exocentric compound is a compound whose meaning does not follow from the meaning of its parts. (Grady, 506) The examples and formations of exocentric compounds are presented as follows:

\section{Droplet}

The word droplet consists of two lexemes. The first one is drop (V), and the second one is let (V). Drop means to allow something to fall by accident or to fall by accident. Then, the word let means to let somebody/something do something used for offering help. However, droplet means a small drop of a liquid. It is obvious that the compound word droplet is an exocentric compound because it is headless and the meaning cannot be drawn from each lexeme.

Fallout

The word fallout consists of two lexemes which are fall (V) and out (Adv). Fall means to drop down from a higher level to a lower level or to suddenly stop standing. Moreover, out means away from the inside of a place or thing. Otherwise, fallout means bad results of a situation or an action. The meaning of fallout cannot be taken literally by referring to the word fall or out. Hence, the word fallout is exocentric compound.

Outbreak

The word outbreak has two lexemes: out (Adv) and break (V). The word out means away from the inside of a place or thing. The word break means to damage something in certain way. Nevertheless, outbreak means the sudden start of something unpleasant, especially violence or a disease. The compound word outbreak usually used to refer the disease, especially COVID19. From the definition of outbreak, there is no correlation between both lexemes out and break. Therefore, the word outbreak is an exocentric compound.

\section{Shortage}

The word shortage has two lexemes which are short $(\mathrm{N})$ and age $(\mathrm{N})$. The word short means measuring or covering a small length or distance, or a smaller length or distance than usual. The word age means the number of years that a person has lived or a thing has existed. Nonetheless, shortage means a situation when there is not enough of the people or things that are needed. The meaning of shortage is really different with the meaning if we take it literally. It is not an age that is short, but it refers to the situation when there is not enough of things. The 
absence of head and the meaning that cannot be drawn literally prove the word shortage is an exocentric compound.

Worldwide

The word worldwide has two lexemes which are world $(\mathrm{N})$ and wide (Adj). The word world means the earth, with all its countries, peoples and natural features. The word wide means measuring a large distance from one side to the other. Nonetheless, worldwide means affecting all parts of the world. From the definition of word worldwide, there is no lexeme that can become the head and dominates the meaning of the whole word. Therefore, it is concluded as an exocentric compound.

\section{CONCLUSION}

This study found that there are 26 compound words that related to COVID-19 topic in The Jakarta Post's Health Column on third week of April 2020. From those data, the writer found three kinds of compound words. Those are compound noun, compound adjectives, and compound verb. The compound nouns are the most dominant compound of all. It has percentage about $86.40 \%$. Meanwhile, the compound adjectives occurred $11.5 \%$ and compound verbs $3.9 \%$. Those compound words have several lexical categories. The most dominant category is from compound nouns which are Noun+Noun and Adjective + Noun. They occurred 14 times and 3 times respectively.

The analysis of compound words meaning reveals that there are $80.76 \%$ endocentric compounds and $19.24 \%$ exocentric compounds. It means that the meaning in most of compound words found in those articles can be defined from its head.

This study is expected to give a better understanding and awareness about COVID-19 pandemic related terms for people. This study is also very limited in the case of the number of pandemic and health related compound words. For the further research, researcher suggest conducting a research on related pandemic and health compound words with much more data and detail analysis on type of compound. Such a research can increase understanding and concern of people about the pandemic. This also gives the contribution on morphology and semantics study.

\section{ACKNOWLEDGMENTS}

The researcher would like to give her greatest gratitude to Dr. Emanuel Sunarto, M. Hum. as the lecturer of Semantics subject in Graduate Program of English Language Studies Universitas Sanata Dharma for giving suggestions and guidance that are useful for finishing this journal.

\section{REFERENCES}

Akmajian, A., Demers, R. A., \& Harnish, R. M. (2010). Linguistics, an introduction to language and communication. Cambridge, Mass: MIT Press.

Bauer, Laurie. (2004). English word-formation. Cambridge: Cambridge University Press.

Bussmann, H. (Ed.). (1998). Routledge dictionary of language and linguistics; translated and edited by Gregory Trauth and Kerstin Kazzazi. London: Routledge.

Booij, Geert. (2005). The grammar of words: An introduction to linguistic morphology. Oxford: Oxford University Press. 
Christianto, Danin. (2019). Compound Words in English. Yogjakarta: LLT Journal: A Journal on Language and Language Teaching. doi.org/10.24071/1lt.2020.230103

Finegan, E. (2008). Language: Its structures and use. Boston, MA: Wadsworth.

Fromkin, V., Rodman, R., \& Hyams, N. M. (2014). An introduction to language. Boston: Thomson/Heinle.

Katamba, Francis. (1993). Morphology. London: Macmillan Press.

Krediler, Charles W. (2002). Introducing English Semantics. New York: Routledge

Liebben, Gary. (2006). The Representation and Processing of Compound Words. New York: Oxford University Press Inc.

Matthews. P.H. (1974). Morphology. Cambridge: Cambridge University.

McCharty, Michael. (2001). English Vocabulary in Upper Intermediate in Use. Cambridge: Cambridge University Press.

Nurazizah, Asti et al., (2018). Compound Words Found in the Republika News Article. PROJECT (Professional Journal of English Education).

O'Grady, William. (2016). Contemporary linguistic analysis. Toronto: Pearson Canada Inc.

Rahayu et al., (2016). A Morphological Analysis on English Compound Words in Five Articles of $B B C$ News. Jember: Artikel Ilmiah Mahasiswa. 